\title{
Effects of RF Power on Electrical and Structural Properties of Sputtered $\mathrm{SnO}_{2}: \mathrm{Sb}$ Thin Films
}

\author{
O. Cevher, M.O. Guler, U. Tocoglu, T. Cetinkaya, H. Akbulut and S.C. Okumus \\ Sakarya University, Engineering Faculty, Department of Metallurgical and Material Engineering \\ Esentepe Campus, Sakarya, Turkey
}

\begin{abstract}
In this work, antimony doped tin oxide $\left(\mathrm{SnO}_{2}: \mathrm{Sb}\right)$ thin films were fabricated using a radio frequency magnetron sputtering system on $\mathrm{Si}$ wafer and glass substrates. The base pressure in the sputtering chamber was $1.0 \mathrm{~Pa}$. The $\mathrm{SnO}_{2}: \mathrm{Sb}$ thin films were deposited for $1.0 \mathrm{~h}$ in a mixture of $\mathrm{Ar}$ and $\mathrm{O}_{2}$ environment with $\mathrm{O}_{2} / \mathrm{Ar}$ ratio of $10 / 90$ at 75 , 100 , and $125 \mathrm{~W}$ RF sputtering powers. The microstructure of $\mathrm{SnO}_{2}: \mathrm{Sb}$ thin films was assessed using a field emission scanning electron microscopy. The crystallographic structure of the sample was determined by X-ray diffraction. The average surface roughness $\left(R_{\mathrm{a}}\right)$ was measured with atomic force microscopy. The electrical resistivity of the deposited films was measured by the four-point-probe method. The thicknesses of the films were measured by surface profiler.
\end{abstract}

DOI: 10.12693/APhysPolA.125.293

PACS: 68.55.-a, 68.55.ag, 81.15.Cd

\section{Introduction}

The $\mathrm{SnO}_{2}$ film is a transparent conductive coating material and an $n$-type semiconductor with a wide band gap (approximately $3.7 \mathrm{eV}$ ) [1] and has tetragonal rutile structure. The $\mathrm{SnO}_{2}$ film shows the best thermal and chemical stability, it is inexpensive, and it has good adhesion to most of the substrates, but it has high resistivity. The optical band gap, resistivity, carrier type, and concentration of $\mathrm{SnO}_{2}$ films can be easily adjusted with addition of a dopant. The most common dopants used for sputter deposited $\mathrm{SnO}_{2}$ thin films are antimony $(\mathrm{Sb})$ and indium (In) [2-4]. The $\mathrm{SnO}_{2}$ films have great potential for application in various fields, such as gas sensors [5], solar cells [6], optoelectronic devices [7], flat panel displays [8], and heat mirrors [9].

The properties of the films are generally affected by preparation conditions such as deposition techniques, substrate temperature, working pressure, types of substrates and the thickness of the films [10]. The conductive antimony doped tin oxide (ATO) films are prepared by various methods such as chemical vapor deposition [11], spray pyrolysis [12], sputtering [13, 14], pulsed-laser deposition (PLD) [15] and dip coating [16]. RF magnetron sputtering is one of the most promising deposition techniques due to the advantages of low deposition temperature, simple processing, whilst yielding the preferred orientation and uniform properties [17], inexpensive equipment and suitability for large area deposition.

The aim of this paper is to investigate the effect of $\mathrm{RF}$ power on the structural and electrical properties of $\mathrm{SnO}_{2}: \mathrm{Sb}$ thin films deposited on silicon wafer and glass substrates by RF magnetron sputtering technique. Our work tends to focus on the changes in the crystallinity, surface roughness, grain size, deposition rate and resistivity of $\mathrm{SnO}_{2}: \mathrm{Sb}$ thin films as a result of $\mathrm{RF}$ power.

\section{Experimental}

The experimental process parameters used in this study are shown in Table. The $\mathrm{SnO}_{2}: \mathrm{Sb}$ thin films were deposited on glass, silicon wafer and stainless steel substrates using RF magnetron sputtering. The target was an $\mathrm{SnO}_{2}: \mathrm{Sb}$ disc $\left(\mathrm{SnO}_{2}: \mathrm{Sb}=90: 10 \%\right.$ in weight, purity $99.99 \%$ ) of a diameter of 50.8 and $6.35 \mathrm{~mm}$ thick. The $\mathrm{RF}$ powers were 75,100 , and $125 \mathrm{~W}$. The flow rate of $\mathrm{Ar}$ and $\mathrm{O}_{2}$ gases was fixed by a TDZM-III mass flow controller. The substrate was not heated deliberately and not measured.

TABLE

Parameters of sputter deposition of the $\mathrm{SnO}_{2}: \mathrm{Sb}$ thin films.

\begin{tabular}{l|l}
\hline \hline sputtering pressure & $1.0 \mathrm{~Pa}$ \\
substrate & glass and silicon wafer \\
substrate temperature & room temperature \\
substrate to target distance & $13.5 \mathrm{~cm}$ \\
deposition time & $60 \mathrm{~min}$ \\
oxygen partial pressure & $10 \%$ \\
{$\left[\left(\mathrm{O}_{2} /\left(\mathrm{O}_{2}+\mathrm{Ar}\right)\right] \cdot 100\right.$} & 75,100, and $125 \mathrm{~W}$ \\
$\mathrm{RF}$ power &
\end{tabular}

The crystalline structure of $\mathrm{SnO}_{2}: \mathrm{Sb}$ thin films was characterized by X-ray diffraction (XRD) technique. The XRD patterns of the deposited $\mathrm{SnO}_{2}: \mathrm{Sb}$ thin films were obtained by an X-ray diffractometer (Rigaku D/MAX 2000 with a multipurpose attachment) using $\mathrm{Cu} K_{\alpha}$ radiation $(\lambda=1.54056 \AA)$. The scan rate used was $2^{\circ} / \mathrm{min}$ and the scan range was from $10^{\circ}$ to be $90^{\circ}$. The grain size as calculated by Scherrer's formula [17]:

$$
D=\frac{0.9 \lambda}{B \cos \theta},
$$

where $D$ is the mean grain size, $\lambda$ is the $\mathrm{X}$-ray wavelength, $B$ is the corrected full-width at half maximum (FWHM) and $\theta$ is the Bragg angle.

The resistivity of the films was also measured. A resistance meter with a four-point probe (Lucas Labs Pro4-4000 probe) was used to measure the electrical resistivity of $\mathrm{SnO}_{2}: \mathrm{Sb}$ thin films. The surface morphology 
of $\mathrm{SnO}_{2}: \mathrm{Sb}$ thin films was investigated by field emission scanning electron microscopy (FESEM) (JSM-6335F). The surface roughness of the films was measured using an atomic force microscope (AFM) (Ntegra). The thickness of the films was measured using a profilometer (KLA Tencor P-6).

\section{Results and discussions}

FESEM micrographs of $\mathrm{SnO}_{2}: \mathrm{Sb}$ thin films deposited with various $\mathrm{RF}$ powers at $10 \%$ oxygen partial pressure were presented in Fig. 1. The $\mathrm{SnO}_{2}: \mathrm{Sb}$ thin films have a relatively smooth and dense surface. Grain agglomerates were also observed. The results show that the nanosized $\mathrm{SnO}_{2}: \mathrm{Sb}$ particles were obtained. The $\mathrm{Si}$ wafer substrates were covered with morphology like Volmer-Weber type growth (Fig. 1) at various RF powers.

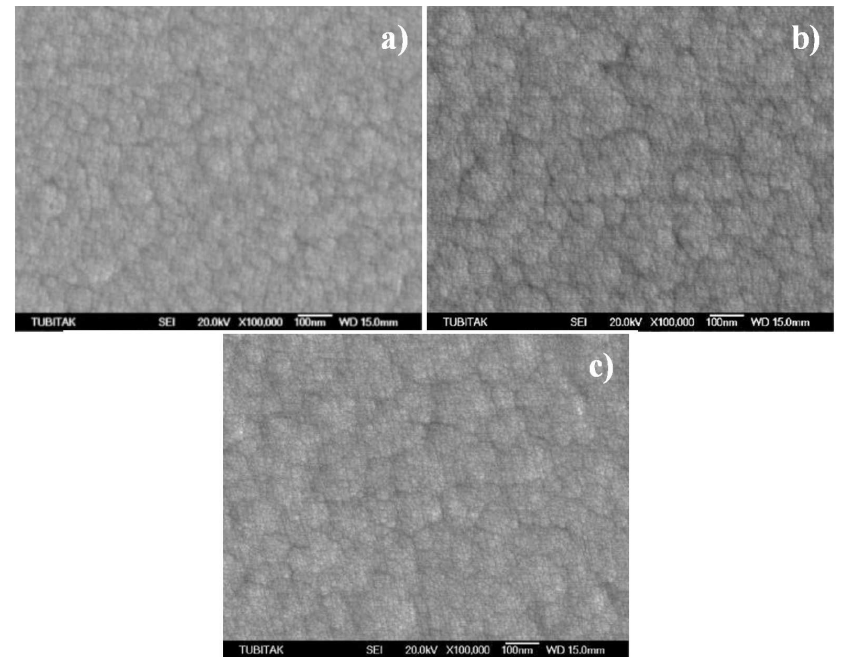

Fig. 1. FESEM micrographs of $\mathrm{SnO}_{2}: \mathrm{Sb}$ thin films deposited at $10 \%$ oxygen partial pressure, (a) $75 \mathrm{~W}$, (b) $100 \mathrm{~W}$, and (c) $125 \mathrm{~W} \mathrm{RF}$ powers.

The crystallographic structure of $\mathrm{SnO}_{2}: \mathrm{Sb}$ thin films deposited with different RF power at $10 \%$ oxygen partial pressure was presented in Fig. 2. The diffraction peaks indicate that tin oxide exists in cassiterite tetragonal ( $\mathrm{ru}-$ tile type) structure (JCPDS card number 00-041-1445). The (110), (101) and (211) diffraction peaks were observed for $\mathrm{SnO}_{2}: \mathrm{Sb}$ thin films deposited with different RF powers in $10 \%$ oxygen partial pressure. The intensity of peaks becomes more intense and sharper with the increase in RF power. This suggests that crystallinity of the resulting film increases with increasing $R F$ power.

Figure 3 shows AFM micrographs of $\mathrm{SnO}_{2}: \mathrm{Sb}$ thin films sputtered with various $\mathrm{RF}$ powers at $10 \%$ oxygen partial pressure.

The surface roughness of $\mathrm{SnO}_{2}: \mathrm{Sb}$ thin films were also illustrated in Fig. 4. The roughness of $\mathrm{SnO}_{2}$ : $\mathrm{Sb}$ thin film increases from 3.516 to $4.778 \mathrm{~nm}$ with the increase of $\mathrm{RF}$ power from $75 \mathrm{~W}$ to $125 \mathrm{~W}$. It is evident from the AFM micrograph that the growth of $\mathrm{SnO}_{2}$ :Sb thin films

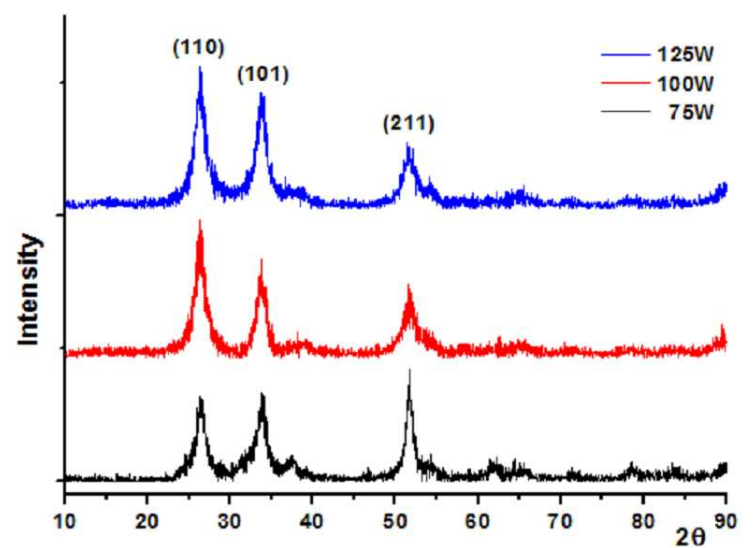

Fig. 2. X-ray diffraction patterns of the ATO thin films deposited with different $\mathrm{RF}$ powers at $10 \%$ oxygen partial pressure.

is in the columnar nature and grain size is increased by increasing $\mathrm{RF}$ power.

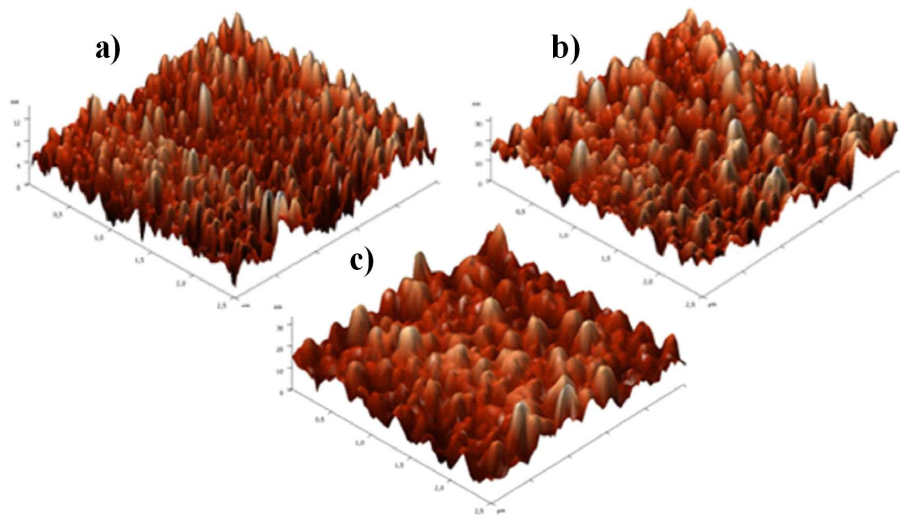

Fig. 3. AFM morphologies of $\mathrm{SnO}_{2}: \mathrm{Sb}$ thin films deposited at $10 \%$ oxygen partial pressure, (a) $75 \mathrm{~W}$, (b) $100 \mathrm{~W}$, and (c) $125 \mathrm{~W}$ RF powers.

The deposition rate and grain size of $\mathrm{SnO}_{2}: \mathrm{Sb}$ thin films deposited with different RF powers at $10 \%$ oxygen partial pressure are shown in Fig. 4. Deposition rate decreases with an increase in RF power at $10 \%$ oxygen partial pressure. As the RF power increased from $75 \mathrm{~W}$ to $125 \mathrm{~W}$, the deposition rate of $\mathrm{SnO}_{2}: \mathrm{Sb}$ thin films increased from $9.68 \mathrm{~nm} / \mathrm{min}$ to $20.51 \mathrm{~nm} / \mathrm{min}$. This can be explained by the fact that the number of sputtered $\mathrm{SnO}$ molecules at the target surface increases owing to the enhancement of bombardment by $\mathrm{Ar}^{+}$ions as the RF power increases and the resulting deposition rate increases [14]. The grain size increases gradually with the RF power. When the RF power is about $75 \mathrm{~W}$, the average grain size is about $9.7 \mathrm{~nm}$, when RF power is increased to $125 \mathrm{~W}$, the grains also increase to about $12.1 \mathrm{~nm}$. From this result, the grain size was observed to get bigger with the increase in the RF power because the increased power caused an increase in the energy of the $\mathrm{Ar}^{+}$ions when 
they collided with the target and then an increase in the surface mobility of the sputtered particles [14].

Figure 4 shows the resistivity of $\mathrm{SnO}_{2}: \mathrm{Sb}$ thin films deposited at different RF powers at $10 \%$ oxygen partial pressure. As the RF power increased from $75 \mathrm{~W}$ to $125 \mathrm{~W}$, the resistivity of $\mathrm{SnO}_{2}: \mathrm{Sb}$ thin films deposited on the glass substrate decreased from 0.159 to $0.0177 \Omega \mathrm{cm}$. This result was very consistent with the other results mentioned previously. That is, the crystallinity was enhanced with higher RF power for the film deposition.

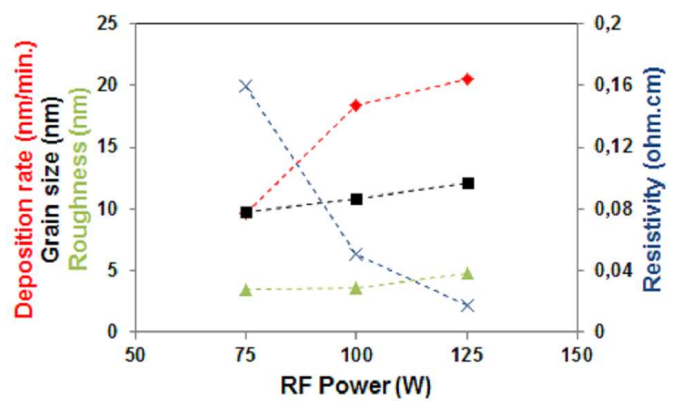

Fig. 4. Deposition rate, grain size, roughness, resistivity of $\mathrm{SnO}_{2}$ : $\mathrm{Sb}$ thin films deposited at $10 \%$ oxygen partial pressure and different RF powers.

\section{Conclusions}

Deposition rate increases with increased in the $R F$ power. The intensity of peaks becomes more intense and sharper with the increase in RF power. The mean grain size increases with increased in the RF power. The average surface roughness of the film increases with the increased in the RF power. The electrical resistivity of $\mathrm{SnO}_{2}: \mathrm{Sb}$ thin film decreases with increased in the $\mathrm{RF}$ power.

\section{Acknowledgments}

This work is supported by the Scientific and Technological Research Council of Turkey (TÜBİTAK) under the contract number 109M464. The authors thank the TÜBİTAK MAG workers for their financial support.

\section{References}

[1] F.J. Arlinghaus, J. Phys. Chem. Solids 35, 931 (1974).

[2] K.Y. Rajpure, M.N. Kusumade, M.N. Neumann-Spallart, C.H. Bhosale, Mater. Chem. Phys. 64, 184 (2000).

[3] T. Kawabe, S. Shimomura, T. Karasuda, K. Tabata, E. Suzuki, Y. Yamaguchi, Surf. Sci. 448, 101 (2000).

[4] K.L. Chopra, S. Major, D.K. Pandya, Thin Solid Films 102, 1 (1983).

[5] D. Haridas, K. Sreenivas, V. Gupta, Sensors Actuat. B 133, 270 (2008).

[6] J.A. Ayllon, M. Lira-Cantu, Appl. Phys. A 95, 249 (2009).

[7] R.E. Presley, C.L. Munsee, C.H. Park, D. Hong, J.F. Wager, D.A. Keszler, J. Phys. D, Appl. Phys. 37, 2810 (2004).

[8] M.R. Cássia-Santos, V.C. Sousa, M.M. Oliveira, F.R. Sensato, W.K. Bacelar, J.W. Gomes, E. Longo, E.R. Leite, J.A. Varela, Mater. Chem. Phys. 90, 1 (2005).

[9] G. Frank, E. Kaur, H. Kostlin, Sol. Energy Mater. 8, 387 (1983).

[10] L.P. Peng, L. Fang, X.F. Yang, H.B. Ruan, Y.J. Li, Q.L. Huang, C.Y. Kong, Physica E 41, 1819 (2009).

[11] J. Kane, H.P. Schweizer, W. Kern, J. Electrochem. Soc. 123, 270 (1976).

[12] A.R. Babar, S.S. Shinde, A.V. Moholkar, C.H. Bhosale, J.H. Kim, K.Y. Rajpure, J. Semicond. 32, 053001 (2011).

[13] H.L. Ma, X.T. Hao, J. Ma, Y.G. Yang, J. Huang, D.H. Zhang, X.G. Xu, Appl. Surf. Sci. 191, 313 (2002).

[14] S.U. Lee, J.H. Boo, B. Hong, Jpn. J. Appl. Phys. 50, 01AB10 (2011).

[15] H. Kim, A. Pique, Appl. Phys. Lett. 84, 218 (2004).

[16] T.M. Hammad, N.K. Hejazy, Int. Nano Lett. 2, 7 (2012).

[17] B.D. Cullity, Elements of X-ray Diffraction, AddisonWesley, Massachusetts 1956. 